\title{
Pengaruh waktu perendaman terhadap bahan tumpatan glass ionomer cement dalam larutan asam asetat
}

\author{
${ }^{1}$ Alga Tanga \\ ${ }^{2}$ Youla A. Assa \\ ${ }^{3}$ Michael A. Leman \\ ${ }^{1}$ Kandidat Skripsi Program Studi Pendidikan Dokter Gigi Fakultas Kedokteran \\ ${ }^{2}$ Bagian Biokimia Fakultas Kedokteran \\ ${ }^{3}$ Program Studi Pendidikan Dokter Gigi Fakultas Kedokteran \\ Universitas Sam Ratulangi Manado \\ Email: alga.tanga@yahoo.com
}

\begin{abstract}
Dental caries is commonly found among modern people with various age, ranged from children, teenager to adult. This indicates the increasing needs of dental caries care. One of dental caries treatments is filling the tooth by using Glass Ionomer Cement (GIC). GIC is a type of filling material with low resistance against acid. This study aimed to find out whether the submersion time affected the GIC filling. This was an experimental study with a posttest only control group design. Samples were 16 round shaped GIC fillings, divided into two groups: treatment group using $1 \%$ acetic acid solution and control group using artificial saliva. Each of both groups were divided into four groups according to the submersion time; 5 minutes, 10 minutes, 15 minutes, and 20 minute. Samples were submersed at $37^{\circ} \mathrm{C}$ in the incubator. Solubility was measured by using spectrophotometer and data were analyzed statistically by using SPSS. Normality was tested by using the Shapiro-Wilk test. Data were analyzed by using Pearson correlation test. The results showed a p value of $>0.05$ among tratment. Conclusion: Submersion time did not affec the GIC fillings.
\end{abstract}

Keywords: acetic acid, glass ionomer cement, GIC fillings.

Abstrak: Karies gigi merupakan masalah kesehatan yang masih sering dialami oleh masyarakat saat ini dan dijumpai pada berbagai golongan usia, mulai dari anak-anak, remaja dan dewasa. Hal ini menyebabkan kebutuhan perawatan karies gigi semakin meningkat. Salah satu cara perawatan karies gigi yaitu dengan melakukan penumpatan. Glass ionomer cement (GIC) merupakan salah satu bahan tumpatan gigi yang sering digunakan. GIC memiliki daya tahan rendah terhadap kondisi yang asam. Penelitian ini bertujuan untuk mengetahui jika ada pengaruh waktu perendaman terhadap bahan tumpatan GIC. Penelitian ini merupakan penelitian ekperimental dengan rancangan posttest only with control group design. Jumlah sampel yang digunakan sebanyak 16 tumpatan GIC yang telah dibentuk seperti lingkaran dan dibagi dalam dua kelompok besar yaitu kelompok perlakuan menggunakan larutan asam asetat $1 \%$ dan kelompok kontrol menggunakan saliva buatan. Kedua kelompok ini kemudian masing-masing dibagi lagi menjadi empat kelompok sesuai dengan waktu perendaman yaitu 5 menit, 10 menit, 15 menit, dan 20 menit. Sampel direndam dengan suhu $37^{\circ} \mathrm{C}$ menggunakan inkubator. Pengukuran kelarutan menggunakan spektrofotometer dan hasil penelitian dianalisis secara statistik dengan program SPSS. Uji normalitas data menggunakan uji Shapiro-Wilk. Data dianalisis dengan uji korelasi Pearson. Hasil analisis menunjukkan nilai p $>0,05$ pada perlakuan. Simpulan: Waktu perendaman tidak berpengaruh secara bermakna terhadap bahan tumpatan GIC.

Kata kunci: asam asetat, glass ionomer cement, tumpatan GIC 
Karies gigi merupakan masalah kesehatan yang masih ditemukan baik di negara maju maupun di negara-negara berkembang. ${ }^{1} \mathrm{Di}$ Indonesia, berdasarkan laporan hasil Riset Kesehatan Dasar (RISKESDAS) tahun 2013,indeks Decay, Missing, Filling-Teeth $(D M F-T)$ pada usia $\geq 12$ tahun yaitu sebesar rata-rata 4,6 dengan nilai masingmasing: $\quad D-T=1,6 ; \quad M-T=2,9 ; \quad F-T=0,08$; yang berarti kerusakan gigi penduduk Indonesia 460 buah gigi per 100 orang. Provinsi Sulawesi Utara berada pada peringkat ketujuh dengan indeks DMF$T=5,4$ yang berarti lebih tinggi dari ratarata indeks $D M F-T$ Indonesia. Jumlah gigi permanen yang mengalami karies di provinsi Sulawesi Utara yaitu $\pm 1,9$ dan berada pada peringkat ketujuh dari 33 provinsi di Indonesia. ${ }^{2}$

Salah satu cara untuk merawat karies gigi yaitu dengan melakukan penumpatan gigi yang karies agar gigi dapat kembali ke bentuknya semula dan berfungsi dengan baik. Prosedur penumpatan gigi merupakan suatu perawatan yang bertahap dimulai dengan membersihkan jaringan gigi yang sudah rusak oleh bakteri dan merapikan bentuk kavitasnya kemudian mengaplikasikan bahan tumpatan ke dalam kavitas gigi yang sudah dibersihkan dan dirapikan bentuknya. ${ }^{3}$

Saat ini, terdapat berbagai macam bahan tumpatan yang digunakan oleh dokter gigi, seperti resin komposit, amalgam, dan glass ionomer cement (GIC). Hal ini memberi kesempatan bagi pasien maupun dokter gigi untuk memilih bahan tumpatan yang diinginkan berdasarkan harga ataupun estetiknya dan tentunya berdasarkan pertimbangan-pertimbangan tertentu dari dokter gigi. ${ }^{3}$

Glass ionomer cement merupakan salah satu bahan tumpatan dalam ilmu kedokteran gigi yang digunakan pada saat ini. Semen ini dibuat untuk tambalan estetik pada gigi anterior dan dianjurkan untuk penumpatan gigi dengan preparasi kavitas kelas III dan V. Semen ini juga menghasilkan ikatan adhesi yang sangat kuat dengan struktur gigi, sehingga berguna untuk restorasi konservatif pada daerah yang mengalami erosi. Salah satu hal yang menarik dari semen ini adalah sifat antikariogeniknya. ${ }^{4}$

Daerah Minahasa di Sulawesi Utara merupakan daerah yang terkenal dengan berbagai macam makanan tradisionalnya. Salah satu makanan tradisional yang banyak diperjualbelikan dan dikonsumsi oleh masyarakat di Minahasa ialah gohu. Makanan ini ialah makanan yang terbuat dari campuran berbagai macam bahan makanan terutama buah pepaya, dan memiliki kuah yang sifatnya asam karena mengandung asam asetat dan lebih sering dikenal dengan nama asam cuka. Asam cuka yang digunakan untuk membuat bahan makanan ini ialah asam cuka yang mudah didapatkan di pasaran.

Hasil penelitian yang dilakukan oleh Markovic et al menunjukkan bahwa GIC tidak terlalu tahan terhadap lingkungan dengan $\mathrm{pH}$ rendah dan dapat mengalami kerusakan yang nyata. $^{5}$

Penelitian ini bertujuan untuk mengetahui pengaruh waktu perendaman terhadap bahan tumpatan glass ionomer cement dalam larutan asam asetat.

\section{BAHAN DAN METODE PENELITIAN}

Penelitian ini menggunakan metode eksperimental dengan rancangan posttest only with control group design. Penelitian dilakukan di Laboratoriun Kimia, Poltekes Kemenkes Manado, Jurusan Gizi pada bulan Februari-November 2015. Bahan tumpatan yang digunakan ialah glass ionomer cement konvensional Tipe II merek GC Glass Ionomer yang dibentuk seperti lingkaran dengan diameter $6 \mathrm{~mm}$ dan tebal $2 \mathrm{~mm}$. Jumlah bahan tumpatan GIC yang digunakan dalam penelitian ini sebanyak enambelas tumpatan. Delapan tumpatan digunakan pada kelompok perlakuan dan delapan tumpatan digunakan pada kelompok kontrol. Kelompok perlakuan dan kelompok kontrol masingmasing dibagi lagi menjadi 4 kelompok berdasarkan waktu perendaman, yaitu 5 menit, 10 menit, 15 menit, dan 20 menit; sehingga seluruhnya terdapat delapan kelompok. Setiap kelompok menggunakan 
2 tumpatan yang direndam. Kelompok perlakuan menggunakan larutan asam asetat $1 \%$ dengan $\mathrm{pH}=3,01$ sedangkan kelompok kontrol menggunakan saliva buatan dengan $\mathrm{pH}=6,8$. Tumpatan direndam berdasarkan waktu perendaman yang telah ditentukan pada masing-masing kelompok kemudian jumlah bahan tumpatan GIC yang larut dalam larutan asam asetat dan saliva buatan pada setiap kelompok diukur menggunakan Spektrofotometer UV-VIS. Data hasil penelitian dianalisis dengan uji korelasi Pearson.

\section{HASIL PENELITIAN}

Tabel 1. pH awal larutan asam asetat dan saliva buatan

\begin{tabular}{cc}
\hline Jenis larutan & $\mathrm{pH}$ \\
\hline Larutan asam asetat & 3,01 \\
Saliva buatan & 6,8 \\
\hline
\end{tabular}

Tabel 2. Hasil pengukuran kelarutan bahan tumpatan GIC padakelompok perlakuan dan kelompok kontrol

\begin{tabular}{lcccc}
\hline \multicolumn{2}{c}{ Kelompok Perlakuan } & \multicolumn{2}{c}{ Kelompok Kontrol } \\
\hline \multicolumn{1}{c}{$\begin{array}{c}\text { Nama } \\
\text { Kelompok }\end{array}$} & $\begin{array}{c}\text { Kelarutan } \\
(\mathrm{ppm})\end{array}$ & \multicolumn{1}{c}{$\begin{array}{c}\text { Nama } \\
\text { Kelompok }\end{array}$} & $\begin{array}{c}\text { Kelarutan } \\
(\mathrm{ppm})\end{array}$ \\
\hline $\begin{array}{l}\text { Kelompok 1 (5 } \\
\text { menit) }\end{array}$ & 1,00 & $\begin{array}{l}\text { Kelompok } \\
\text { (5 menit) }\end{array}$ & 1,00 \\
$\begin{array}{l}\text { Kelompok 2 } \\
\text { (10 menit) }\end{array}$ & 3,00 & $\begin{array}{l}\text { Kelompok } \\
\text { (10 menit) }\end{array}$ & 1,33 \\
$\begin{array}{l}\text { Kelompok 3 } \\
\text { (15 menit) }\end{array}$ & 1,33 & $\begin{array}{l}\text { Kelompok } \\
\text { (15 menit) }\end{array}$ & 1,33 \\
$\begin{array}{l}\text { Kelompok 4 } \\
\text { (20 menit) }\end{array}$ & 1,00 & $\begin{array}{l}\text { Kelompok } \\
\text { (20 menit) }\end{array}$ & 1,50 \\
\hline
\end{tabular}

Setelah dilakukan uji korelasi Pearson, diperoleh hasil bahwa tidak terdapat hubungan yang bermakna antara waktu perendaman dengan bahan tumpatan GIC (p >0,05), dan kekuatan hubungannya sangat lemah $(r<0,60)$.

Tabel 3. Hasil uji korelasi Pearson

\begin{tabular}{ccc}
\hline & & GIC \\
\hline Waktu & $\mathrm{r}$ & 0,066 \\
perendaman & $p$ & $>0,05$ \\
& $\mathrm{n}$ & 8 \\
\hline
\end{tabular}

\section{BAHASAN}

Kelarutan bahan tumpatan GIC dapat terjadi baik pada perendaman dengan asam asetat sebagai kelompok perlakuan maupun dengan saliva buatan sebagai kelompok kontrol. Secara sederhana, dilihat dari sudut pandang molekul, proses pelarutan terjadi dalam tiga tahap yang berbeda, yaitu: 1) tahap terjadinya pemisahan antarmolekul pelarut; 2) tahap terjadinya pemisahan antarmolekul zat terlarut; dan, 3) tahap bercampurnya molekul pelarut dengan mulekul zat terlarut. Jika suatu zat (zat terlarut) larut dalam zat lainnya (pelarut), partikel zat terlarut akan menyebar ke seluruh pelarut. ${ }^{6}$ GIC tidak terlalu tahan terhadap lingkungan dengan $\mathrm{pH}$ yang rendah. ${ }^{5}$ Hal ini berarti bahwa partikel GIC yang terlepas pada larutan dengan $\mathrm{pH}$ rendah akan lebih banyak dibandingkan dengan partikel yang terlepas pada larutan dengan $\mathrm{pH}$ yang mendekati $\mathrm{pH}$ normal.

Dari hasil penelitian, terlihat bahwa pada kelompok perlakuan terjadi peningkatan jumlah kelarutan pada kelompok 2 dan mengalami penurunan jumlah kelarutan pada kelompok berikutnya yaitu kelompok 3 dan 4 . Hal ini disebabkan karena tidak adanya lagi molekul pada GIC yang dapat berikatan dengan molekul pada asam asetat sehingga tidak ada lagi partikel GIC yang dapat larut dalam larutan asam asetat.Pada kelompok kontrol, jumlah kelarutan terus mengalami peningkatan seiring dengan bertambahnya waktu perendaman kecuali pada kelompok 6 dan 7 karena $\mathrm{pH}$ saliva buatan yang lebih mendekati $\mathrm{pH}$ normal sehingga lebih sedikit partikel dari GIC yang dapat terlepas. Hal ini menyebabkan dibutuhkannya waktu yang lebih lama untuk membentuk ikatan molekul antara GIC dengan molekul saliva buatan sehingga proses kelarutan pun berjalan lebih lambat. Hasil ini sama dengan hasil penelitian yang dilakukan oleh Markovic et al yang menunjukkan bahwa GIC tidak terlalu tahan terhadap lingkungan dengan $\mathrm{pH}$ yang rendah dengan nilai $\mathrm{pH} 2,5$ dan 5,5.

Keterbatasan penelitian ini yaitu tidak dilakukan pengukuran seluruh larutan 
pelarut yang digunakan untuk merendam bahan tumpatan GIC, sehingga kemungkinan masih terdapat sisa partikel-partikel GIC yang larut dalam larutan.

\section{SIMPULAN}

Waktu perendaman tidak memiliki pengaruh yang bermakna terhadap bahan tumpatan glass ionomer cement.

\section{SARAN}

Perlu penelitian lanjutan mengenai partikel-partikel yang terlepas pada saat perendaman, perubahan warna GIC, serta bentuk permukaan dan kekerasan bahan tumpatan GIC.

\section{UCAPAN TERIMA KASIH}

Ucapan terima kasih disampaikan pada drg. P. S. Anindita, Sp.Orto, dr. S.H.R. Ticoalu, M.Kes, AIFO, serta semua pihak yang baik secara langsung maupun tidak langsung telah menumbuhkan ide atau gagasan dalam pemikiran penulis sehingga dapat menyelesaikan artikel ini.

\section{DAFTAR PUSTAKA}

1. Sondang P, Hamada T. Menuju gigi dan mulut sehat: pencegahan dan pemeliharaan. Medan: USU Press, 2008; p. 4.

2. Badan Penelitian dan Pengembangan Kesehatan Kementerian Kesehatan RI. Riset kesehatan dasar: RISKESDAS 2013 [serial online] 2013; [internet]. Availablefrom:URL: http://www.depkes.go.id/resources/do wnload/general/Hasil\%20Riskesdas\% 202013.pdf. Acessed April 14, 2015.

3. Rahmadhan AG. Serba-serbi kesehatan gigi dan mulut. In: Handayani NP, editor. Jakarta: Bukuné, 2010; p.13440.

4. Anusavice KJ. Phillips: Buku ajar ilmu bahan kedokteran gigi (10th ed). In: Juwono L, editor. Jakarta: EGC, 2003; p. 449, 452.

5. Markovic DLj, Petrovic BB, Peric TO. Fluoride content and recharge ability of five glassionomer dental materials. BMC Oral Health [serial online] 2008 Jul; 21(8): [internet]. Available from: URL:

http://www.biomedcentral.com/conte nt/pdf/1472-6831-8-21.pdf. [cited October 3, 2015].

6. Chang R. Kimia dasar: konsep-konsep inti (3rd ed). Jakarta: Erlangga, 2005; p. 4-5. 